\title{
Editorial: Students as partners in course delivery
}

\author{
Gita Sedghi \\ University of Liverpool
}

The concept of students as partners has attracted increased attention in higher education during the last decade. Healey et al. (2014) describe students as partners as 'a relationship in which all involved - students, academics, professional services staff, senior managers, students' unions, and so on - are actively engaged in and stand to gain from the process of learning and working together'.

As strong advocates of 'students as partners' practices, the writers in this section of the Compendium found themselves in a difficult situation when trying to engage in genuine and meaningful partnership with students during the pandemic. The key challenge they faced was how to involve students in dialogue about online and blended modules as they were being developed, rather than after they were delivered. The mechanisms for student feedback in existing quality assurance processes were not adequate for the emergency redesign of modules. In this crisis, universities also seemed to be less successful at assuring students of the quality education they were receiving.

The pieces in this section show us how educators enabled and empowered students to cocreate design and delivery solutions that worked for them while respecting the boundaries of the institutional limitations. Developing informed reflection skills that relied on students' active involvement rather than merely attending sessions and taking notes was more difficult than ever. Course provision is a complex endeavour requiring thorough planning of learning objectives, pedagogies, classroom procedures, materials, and assessment. Moving these to a different mode of delivery takes time, effort, and relevant training, none of which were available during the rapid switch to online teaching due to Covid-19.

The coronavirus pandemic gave universities a chance to reflect on new ways to embrace student partnership. Students contributed to vital aspects of the university's pandemic response, including developing new digital learning and teaching principles, guidance for 
blended learning, and support for those self-isolating. This section of the JLDHE Compendium showcases the educators and learning developers' initiatives to co-create curricula with students and engage them in co-developing the policies underpinning their learning and its outcomes.

The authors of the papers that follow draw on the lessons learned and recommend ways that enable students to act as agents of change in designing effective strategies to support their learning and attainment - beyond the classroom. The partnership approach to designing and assuring the quality of education provides an effective and constructive way to build trust in online and other novel or changed ways of doing things. The pandemic showed how emphasising communication with the students and giving them some agency in making decisions around transition create a comfortable learning environment that may mitigate the effects of uncertainty and stress. When the students had clear explanations of how the classes would run and what issues may arise, they felt less stressed and overwhelmed with the new technologies and class procedure adaptations. Treating students as design partners does not mean giving students a free choice, but it does mean giving them a choice and honouring it.

\section{References:}

Healey, M., Flint, A. and Harrington, K. (2014) Engagement through partnership: students as partners in learning and teaching in higher education. York: The Higher Education Academy. 